\title{
Optical, structural and morphological study of CdS nanoparticles: role of sulfur source
}

Mahesh M. Kamble MSc, MPhil, PhD

Assistant Professor, PDEA's Anantrao Pawar College, Pune, India (Orcid:0000-0001-6835-5674)

Sachin R. Rondiya MSc, MPhil, PhD

Postdoctoral Research Associate, School of Chemistry, Cardiff University, Cardiff, UK (Orcid:0000-0003-1350-1237)

Bharat R. Bade MSC, MPhil

Senior Research Fellow, School of Energy Studies, Savitribai Phule Pune University, Pune, India (Orcid:0000-0001-8450-6807)

Kiran B. Kore MSC

Research Scholar, School of Energy Studies, Savitribai Phule Pune University, Pune, India (Orcid:0000-0003-0536-2142)

\author{
Mamta P. Nasane MSc \\ Research Scholar, School of Energy Studies, Savitribai Phule Pune \\ University, Pune, India (Orcid:0000-0002-4273-9941)
}

Nelson Y. Dzade MSc, MPhil, PhD

EPSRC Innovation Research Fellow, School of Chemistry, Cardiff University, Cardiff, UK (Orcid:0000-0001-7733-9473)

Adinath M. Funde MSc, MPhil, PhD

Assistant Professor, School of Energy Studies, Savitribai Phule Pune University, Pune, India (corresponding author: adinathf@gmail.com) (Orcid:0000-0002-6353-1103)

Sandesh R. Jadkar MSc, PhD

Professor, Department of Physics, Savitribai Phule Pune University, Pune,

India (corresponding author: sandesh@physics.unipune.ac.in)

(Orcid:0000-0002-0610-7242)

Cadmium sulfide (CdS) nanoparticles were synthesized by using a simple and low-cost home-made hot-injection method at a low process temperature using different sulfur (S) sources. The effects of sulfur concentration on the structural, morphological and optoelectronic properties of the synthesized cadmium sulfide films were studied using a range of characterization techniques: X-ray diffraction (XRD), Raman spectroscopy, field-emission scanning electron microscopy (FESEM) and ultraviolet-visible spectroscopy. The XRD studies revealed the formation of hexagonal-type cadmium sulfide nanoparticles. The varying morphology dependence on the sulfur source was ascertained from FESEM analysis. The longitudinal optical phonon vibrational modes of cadmium sulfide were assigned in Raman spectra at 300 and $600 \mathrm{~cm}^{-1}$. The bandgap of the cadmium sulfide particles was estimated to be $2 \cdot 30 \mathrm{eV}$ from Tauc's plots. Consistent with the experimental results, this study's first-principles density functional theory calculations predict the bandgap of cadmium sulfide nanoparticles to increase with decreasing sulfur concentration - $\mathrm{Cd}_{52} \mathrm{~S}_{52}$ $(2.38 \mathrm{eV}), \mathrm{Cd}_{52} \mathrm{~S}_{51}(2.52 \mathrm{eV})$ and $\mathrm{Cd}_{52} \mathrm{~S}_{50}(2.65 \mathrm{eV})$ - with both the valence and conduction band edges demonstrated to be dominated by sulfur $p$ states.

\section{Notation}

$B$ Tauc's constant, a characteristic parameter of the material independent of the photon energy

$d_{\mathrm{X} \text {-ray }}$ average crystallite size estimated from X-ray diffraction (XRD) analysis

$E_{\mathrm{g}} \quad$ bandgap of the material

hv photon energy

$K \quad$ extinction coefficient

$n_{\mathrm{b}} \quad$ refractive index of bulk cadmium sulfide (CdS)

$n_{\mathrm{f}} \quad$ refractive index of the synthesized film of cadmium sulfide

$\alpha \quad$ absorption coefficient

$\beta \quad$ full width at half maximum of the XRD peak

$\Gamma \quad$ center of the Brillouin zone $\left(\begin{array}{lll}0 & 0 & 0\end{array}\right)$

$\varepsilon(\omega) \quad$ complex dielectric function, function of frequency, $\omega$

$\lambda \quad$ wavelength

$\rho \quad$ relative density of cadmium sulfide films

\section{Introduction}

Photovoltaic devices that convert sunlight into electricity using the photovoltaic effect are an expedient and sustainable method for resolving the problems of energy demand. Nowadays, commercial solar cells are fabricated using silicon wafers, which exhibit superior stability and a high power-conversion efficiency of about
15-20\%. ${ }^{1}$ However, due to the high cost of such solar cells, research is being focused on new device architecture of thin-film perovskite technology. Perovskite solar cells (PSCs) are an innovative type of photovoltaic technology that has exhibited a fast improvement in efficiency from $3 \cdot 8 \%$ in 2009 to $24 \cdot 2 \%$ in 2019. ${ }^{2}$ Cadmium sulfide (CdS) thin films are used as an electrontransport layer instead of a regular titanium dioxide $\left(\mathrm{TiO}_{2}\right)$ layer in PSCs. ${ }^{3,4}$ Cadmium sulfide is also used as a window and a holeblocking layer in cadmium telluride (CdTe)-based solar cells and PSCs, respectively. ${ }^{5}$ Thus, cadmium sulfide is an attractive directbandgap semiconductor material because of several applications in photocatalysis, photonic, optoelectronic and photovoltaic devices. ${ }^{6}$ A variety of preparation methods with different precursors of cadmium (Cd) and sulfur ( $\mathrm{S}$ ) have been used to synthesize cadmium sulfide nanocrystals to obtain desired physical, structural and optoelectronic properties. These synthesis techniques include the sol-gel method, ${ }^{7}$ hydrothermal method, ${ }^{8}$ solvothermal method, ${ }^{9}$ coprecipitation, ${ }^{10}$ photochemical method, polyol synthesis, ${ }^{11}$ ion implantation, ${ }^{12}$ microwave-assisted sythesis ${ }^{13}$ and electron-beam evaporation. ${ }^{4}$ These methods are either expensive, hazardous, moisture sensitive, extremely toxic or energy intensive. Therefore, the fabrication of device-quality cadmium sulfide materials with a lower cost through a simple approach is still a challenge for both industries and researchers. The hot-injection 
method (HIM) is an attractive option owing to its capability to synthesize device-quality cadmium sulfide nanocrystals. HIM is safe, low-cost, environment-friendly and suitable for large-scale production of cadmium sulfide nanocrystals with high stability. The structural, optical, morphological and electrical properties of cadmium sulfide nanocrystals can be precisely controlled by changing synthesis parameters such as reaction time, process temperature and injection temperature.

\section{Experimental section}

Cadmium sulfide nanocrystals were prepared by using HIM with oleylamine as the solvent, surfactant and capping ligand. Figure 1 shows a schematic diagram of the facile hot-injection set up used for the synthesis of cadmium sulfide nanocrystals. Cadmium chloride monohydrate $\left(\mathrm{CdCl}_{2} \cdot \mathrm{H}_{2} \mathrm{O} ; 0 \cdot 2 \mathrm{M}\right)$ was added to $10 \mathrm{ml}$ oleylamine in a $100 \mathrm{ml}$ three-necked flask with one end connected alternately to a vacuum and argon (Ar) gas container, another for sulfur solution injection and the third one for the thermocouple to measure the reaction temperature. The resulting solution was stirred and heated to a constant temperature of $160^{\circ} \mathrm{C}$ under vacuum and purged with argon gas for $30 \mathrm{~min}$. The argon purging procedure was repeated ten times to ensure complete elimination of air from the system. Once the cadmium-oleylamine complex turned into a light yellow solution, the temperature was raised to $230^{\circ} \mathrm{C}$ for an hour, since the crystallite size and morphology of resultant nanoparticles depend on this reaction temperature.

In the first set of experiments, the elemental sulfur powder (S1 source, $0 \cdot 5-2.5 \mathrm{M}$ ) was dissolved in $5 \mathrm{ml}$ oleylamine and stirred gently at a constant heating temperature of $80^{\circ} \mathrm{C}$ for $45 \mathrm{~min}$. The resulting sulfur solution was then injected into the cadmium-oleylamine complex, and the mixture solution was heated to a reaction temperature of $230^{\circ} \mathrm{C}$ and aged for half an hour, forming a homogeneous yellowish solution. This solution was then allowed to cool at room temperature. The whole reaction was carried out in an alternate vacuum and argon atmosphere. The same procedure was repeated for the second set of experiments in which another sulfur source (S2 source, $0 \cdot 15-0 \cdot 35 \mathrm{M}), 50 \%$ each of thiourea $\left(\mathrm{NH}_{2} \mathrm{CSNH}_{2}\right)$ and sodium sulfide flakes pract $\left(\mathrm{Na}_{2} \mathrm{~S} \cdot X \mathrm{H}_{2} \mathrm{O}\right)$ was used. The cadmium sulfide nanocrystals were dispersible in organic solvents such as toluene and isopropanol; hence, $5 \mathrm{ml}$ of toluene and $40 \mathrm{ml}$ of isopropanol were added in order to precipitate the cadmium sulfide nanocrystals. The precipitate was retrieved by centrifugation at 2500 revolutions per min, producing colloidal yellowish cadmium sulfide nanocrystals. This colloidal precipitate of cadmium sulfide was then developed into a thin film on soda lime glass by using the doctor blade method. ${ }^{14}$ The films were posttreated at a temperature of $50^{\circ} \mathrm{C}$ to dry the film. The intention of using this low temperature was to avoid energy-intensive steps. The resultant cadmium sulfide films were then taken out for characterization.

\subsection{Characterizations}

The optical bandgap and optical constants - namely, refractive index, extinction coefficient and relative density - of as-deposited cadmium sulfide films was deduced using an ultraviolet-visible (UV-Vis) spectrophotometer (Jasco, V-670 model) in the

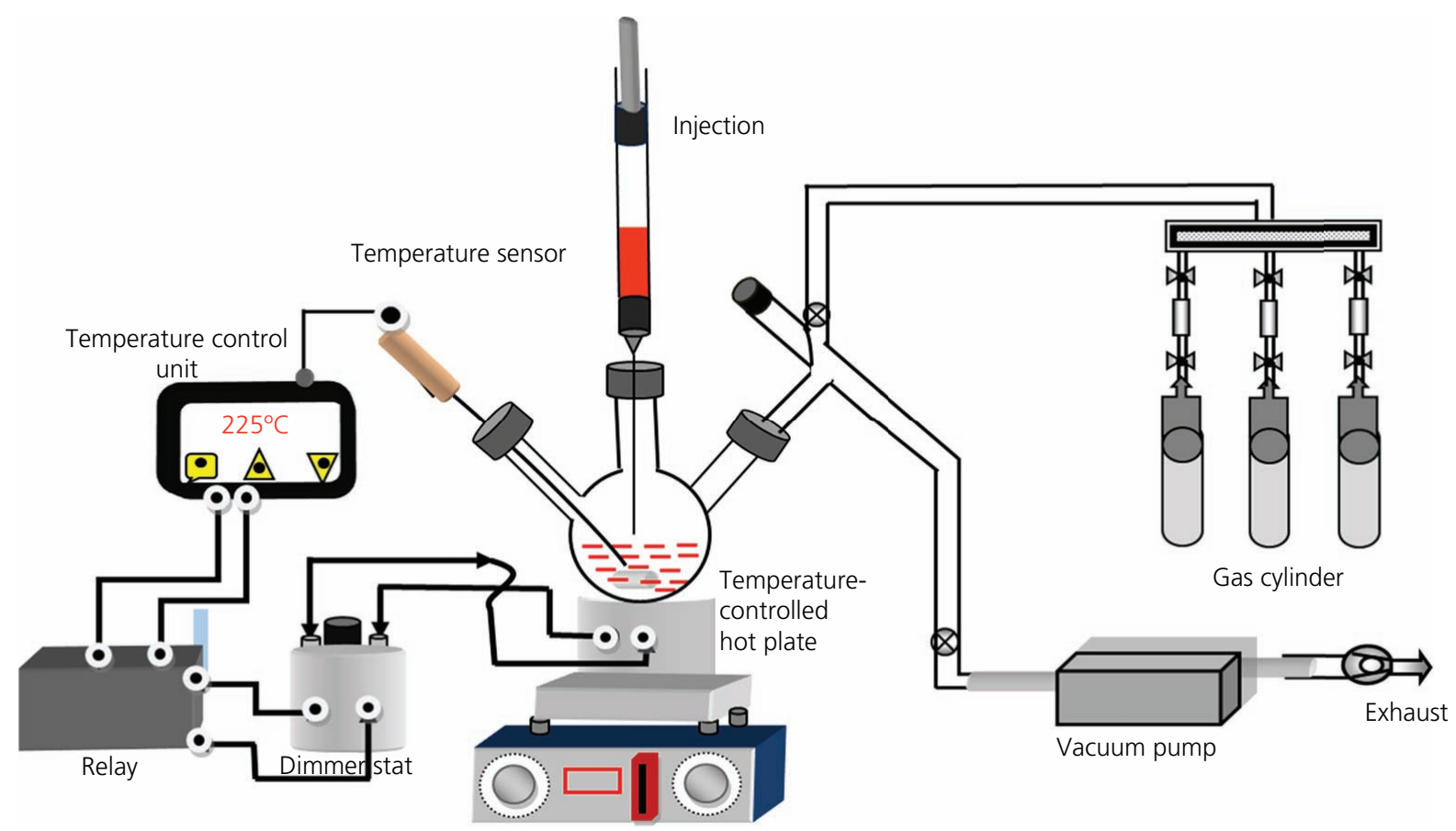

Figure 1. Schematic diagram of the hot-injection technique experimental set-up 
wavelength range $250-800 \mathrm{~nm}$. The Raman spectra of cadmium sulfide films were recorded with a Horibra Jobin Yvon LabRAM HR apparatus in the range $200-1200 \mathrm{~cm}^{-1}$. The spectrometer has backscattering geometry for detection of Raman spectra at a resolution of $1 \mathrm{~cm}^{-1}$. The excitation wavelength of the source was the $532.8 \mathrm{~nm}$ line of a helium $(\mathrm{He})$-neon $(\mathrm{Ne})$ laser. The power of the Raman laser was kept at $1 \mathrm{~mW}$ to avoid laser-induced crystallization in the films. The low-angle X-ray diffraction (XRD) pattern of the cadmium sulfide films was obtained by using an X-ray diffractometer (Bruker D8 Advance, Germany) using the copper $(\mathrm{Cu}) \mathrm{K} \alpha$ line $(\lambda=1.54 \AA)$ at a grazing angle of $1^{\circ}$. The Fourier transform infrared (FTIR) spectra were recorded in the transmission mode by using an FTIR spectrophotometer (Jasco, 6100-type A) in the range 400-4000 $\mathrm{cm}^{-1}$.

\subsection{Computational details}

The electronic structure calculations were performed using the Vienna Ab Initio Simulation Package, ${ }^{15,16}$ a periodic plane wave density functional theory (DFT) software program. Geometry optimization was performed with the Perdew-Burke-Ernzerhof functional ${ }^{17}$ based on the conjugate-gradient algorithm until the residual Hellmann-Feynman forces on all relaxed atoms reached $10^{-3} \mathrm{eV} / \AA$. The interactions between the valence electrons and the cores were described with the projected augmented wave method, ${ }^{18}$ which performs a fully relativistic calculation for the core electrons and treats the valence electrons in a scalar relativistic approximation. ${ }^{19}$ The Brillouin zone of bulk CdS was sampled using a $\Gamma$-centered $5 \times 5 \times 3 \mathrm{k}$-mesh with an energy cutoff of $600 \mathrm{eV}$. For accurate determination of the electronic structures, the screened hybrid functional HSE06 with $25 \%$ Hartree-Fock exchange was used. ${ }^{20}$ The density of states (DOS) of the cadmium sulfide nanoparticles was calculated using the tetrahedron method with Bloch corrections. ${ }^{21}$ The optical properties were calculated from the complex dielectric function $\varepsilon(\omega)=\varepsilon_{1}(\omega)+i \varepsilon_{2}(\omega)$ within the independent-particle formalism.

\section{Results and discussion}

\subsection{XRD study}

The effects of sulfur concentration on the size, crystallinity and crystal phases of the cadmium sulfide films were studied from XRD patterns. The XRD patterns of the films grown at various sulfur concentrations with $\mathrm{S} 1$ and S2 sources are shown in Figures 2(a) and 2(b), respectively. The XRD patterns show peaks at $2 \theta$ values of $24 \cdot 92,26 \cdot 66,28 \cdot 32,36 \cdot 82,43 \cdot 90,48 \cdot 17$ and $52 \cdot 10^{\circ}$, corresponding to the (100), (002), (101), (102), (110), (103) and (112) crystal orientations, respectively. The XRD patterns are well matched with Joint Committee on Powder Diffraction Standards number 01-080-0006 of pure hexagonal cadmium sulfide. As seen from Figures 2(a) and 2(b), the diffraction peaks of all the samples become more intense with increasing sulfur concentrations, indicating improvement in the crystallinity. The crystallinity of cadmium sulfide nanocrystals grown by HIM was found to depend on the $(a)$ molar ratio of cadmium to the sulfur precursor, $(b)$ molar ratio of cadmium and sulfur precursors to the oleylamine capping ligand, (c) reaction temperature and $(d)$ reaction time. ${ }^{22}$ When sulfur solution $\left(80^{\circ} \mathrm{C}\right)$ is injected into the cadmium-oleylamine complex $\left(230^{\circ} \mathrm{C}\right)$, instantaneous formation of cadmium sulfide nuclei takes place. Further heating of the cadmium sulfide complex solution at a temperature of $230^{\circ} \mathrm{C}$ for half an hour resulted in the nucleation cadmium sulfide nanoparticles from monodispersed, free cadmium and sulfur precursors. The slow growth at a relatively high temperature of $230^{\circ} \mathrm{C}$ allows the nanocrystals to anneal and to form nearly defect-free hexagonal-crystal-type cadmium sulfide, which is identical to the bulk lattice.

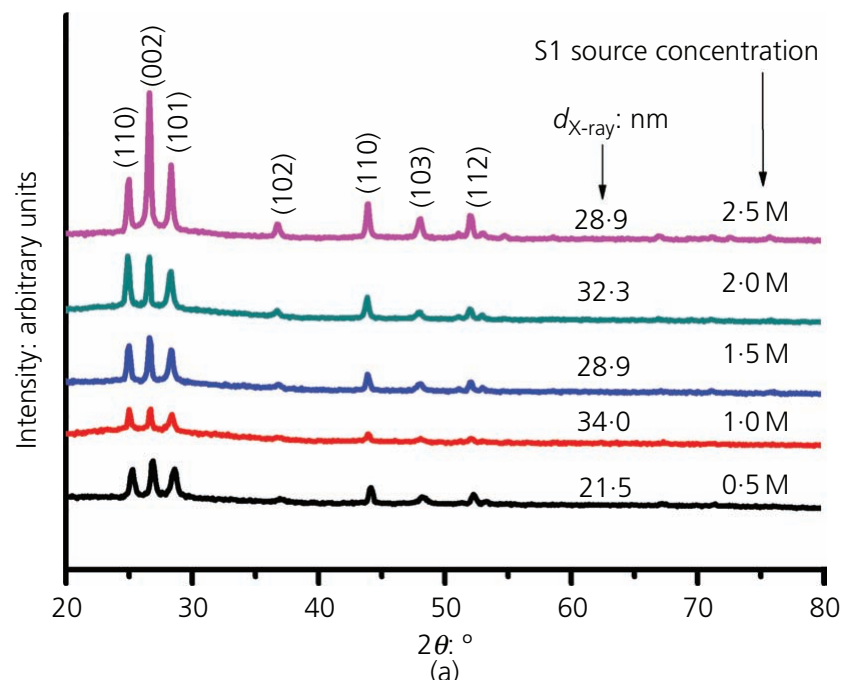

(a)

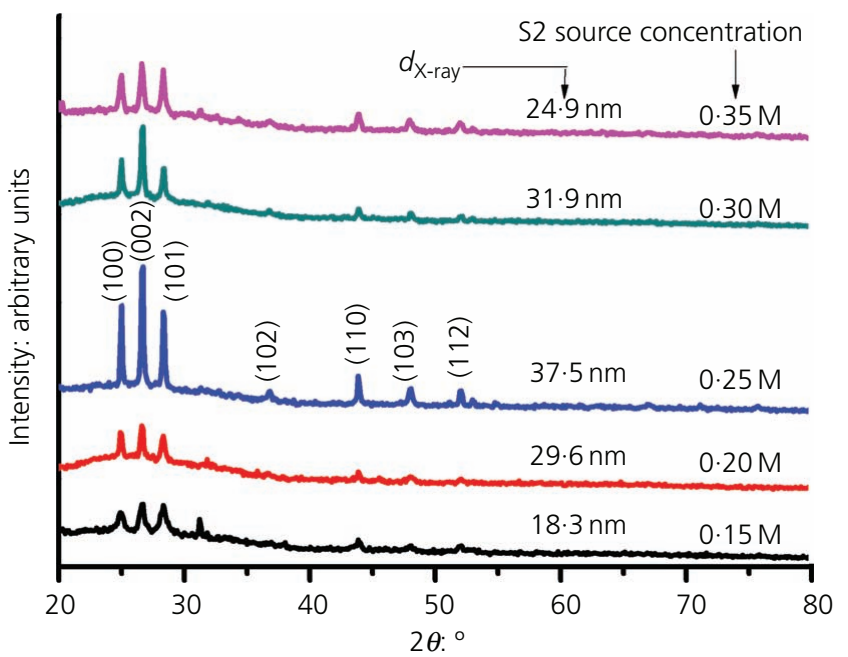

(b)

Figure 2. XRD patterns of the cadmium sulfide films synthesized at different (a) S1 and (b) S2 source concentrations 
The average crystalline size $d_{\mathrm{X} \text {-ray }}$ of cadmium sulfide was calculated corresponding to the strongest peak of (002) at $26.66^{\circ}$

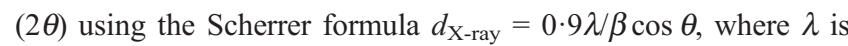
the wavelength of $\mathrm{X}$-rays (1.54 $\AA$ ), $\theta$ is the Bragg angle and $\beta$ is the line width (full width at half maximum) in radians. As shown in Figure 2(a), the average crystallite size in the case of the S1 source was found to vary between $21 \cdot 5$ and $34.0 \mathrm{~nm}$ as the sulfur molar concentration changes from 0.5 to $2.5 \mathrm{M}$. As seen in Figure 2(b), the crystallite size enhances from $18 \cdot 3$ to $37 \cdot 5 \mathrm{~nm}$ with increasing sulfur concentration from $0 \cdot 15$ to $0.25 \mathrm{M}$; with further increasing S2 concentration, the crystalline size decreases. Such behavior is due to the fact that the composition of the initial reactants determines the development of the growth mechanism. ${ }^{23}$ The formation of cadmium sulfide nanocrystals using HIM is demonstrated to follow the Ostwald ripening (OR) principle. ${ }^{24}$ According to the OR principle, small solid particles dispersed in their own saturated solution dissolve and subsequently redeposit on the larger particles in the same solution. That means that the smaller crystals act as fuel for the growth of bigger crystals; hence, the average crystalline size of the cadmium sulfide nanocrystals grown by HIM is large enough in comparison with that by other techniques.

Cadmium sulfide can exist in a cubic or hexagonal structure or sometimes a mixture of both phases. The hexagonal phase has higher optical transmission and good electrical conductivity relative to the cubic phase; hexagonal cadmium sulfide thin films are more suitable to be an n-type window layer for cadmium sulfide solar cells. ${ }^{25}$ Thus, cadmium sulfide grown by HIM has advantages in thin-film solar cells.

\subsection{FTIR analysis}

The FTIR spectra of the cadmium sulfide films deposited at different sulfur concentrations with S1 and S2 sulfur sources are shown in Figures 3(a) and 3(b), respectively. The FTIR technique was used to identify the different bonding configurations present in the cadmium sulfide films. As seen from the FTIR spectra in Figures 3(a) and 3(b), in the higher-energy region, the absorption peaks located nearly at 3618 and $3740 \mathrm{~cm}^{-1}$ can be assigned to the $\mathrm{O}-\mathrm{H}$ stretching of the adsorbed moisture on the cadmium sulfide surface. $^{26}$ The strong absorption band located at $\sim 670 \mathrm{~cm}^{-1}$ is observed in both sets; it corresponds to the $\mathrm{Cd}-\mathrm{S}$ stretching vibrational mode, which confirms the formation of cadmium sulfide. ${ }^{27}$ The FTIR spectra of cadmium sulfide films deposited at different S1 sources is shown in Figure 3(a). These FTIR spectra also exhibit weak absorption bands centered at $\sim 800-950, \sim 1200$ and $\sim 1376-1460 \mathrm{~cm}^{-1}$, which correspond to the $\mathrm{C}-\mathrm{C}$ stretching band, ${ }^{28} \mathrm{C}-\mathrm{CH}$ bending ${ }^{29}$ and sulfate $\mathrm{S}=\mathrm{O}$ group, respectively. ${ }^{30}$ The medium strong absorption bands observed at $1512 \mathrm{~cm}^{-1}$ can be assigned to $\mathrm{N}-\mathrm{H}$ bending vibrations, ${ }^{31}$ which suggest that there are still a few oleylamine ligands bonded with cadmium sulfide after the washing process. The vibrational band at $\sim 1625 \mathrm{~cm}^{-1}$ is assigned to the symmetric bending of the water molecule. ${ }^{32}$ All the samples synthesized at different sulfur concentrations show a predominant vibrational peak located nearly at $1732 \mathrm{~cm}^{-1}$, which corresponds to the carbonyl group $(\mathrm{C}=\mathrm{O}){ }^{33}$ As shown in Figure 3(b), cadmium sulfide films synthesized at different S2 source concentrations show similar bonding configurations as that of the $\mathrm{S} 1$ source. The detection of the $\mathrm{C}=\mathrm{O}$ and $\mathrm{N}-\mathrm{H}$ peaks from the FTIR analysis indicates that oleylamine acts as both a binder and a stabilizer for the synthesis of cadmium sulfide.

\subsection{Raman spectroscopic analysis}

The Raman spectra of the synthesized cadmium sulfide films using the S1 source are shown in Figure 4. The film deposited at $1 \mathrm{M}$ sulfur source shows three distinct peaks with different intensities. The peaks located at 300 and $600 \mathrm{~cm}^{-1}$ are assigned to the

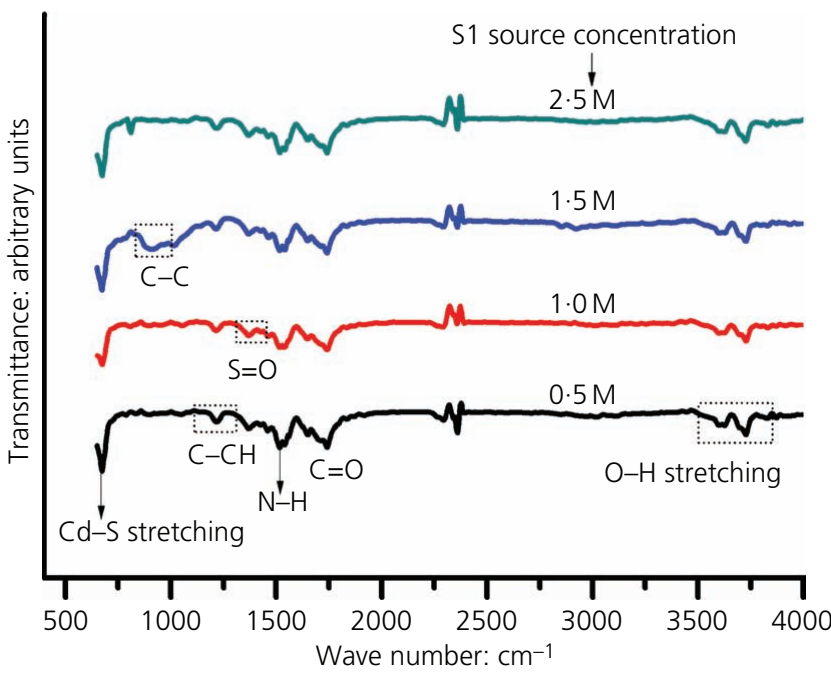

(a)

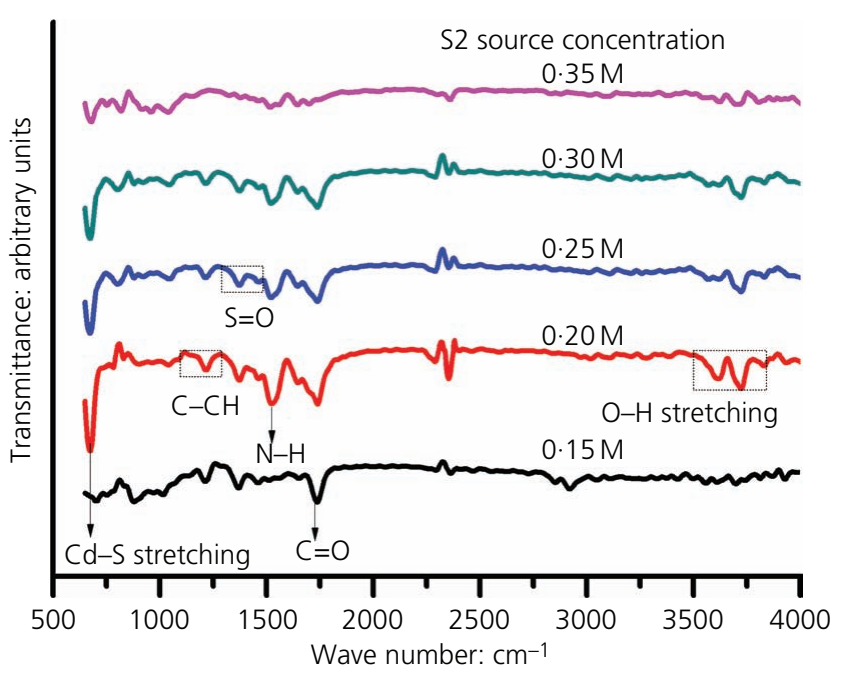

(b)

Figure 3. FTIR spectra of cadmium sulfide films synthesized at different (a) S1 and (b) S2 source concentrations 
Optical, structural and morphological study of CdS nanoparticles: role of sulfur source

Kamble, Rondiya, Bade et al.

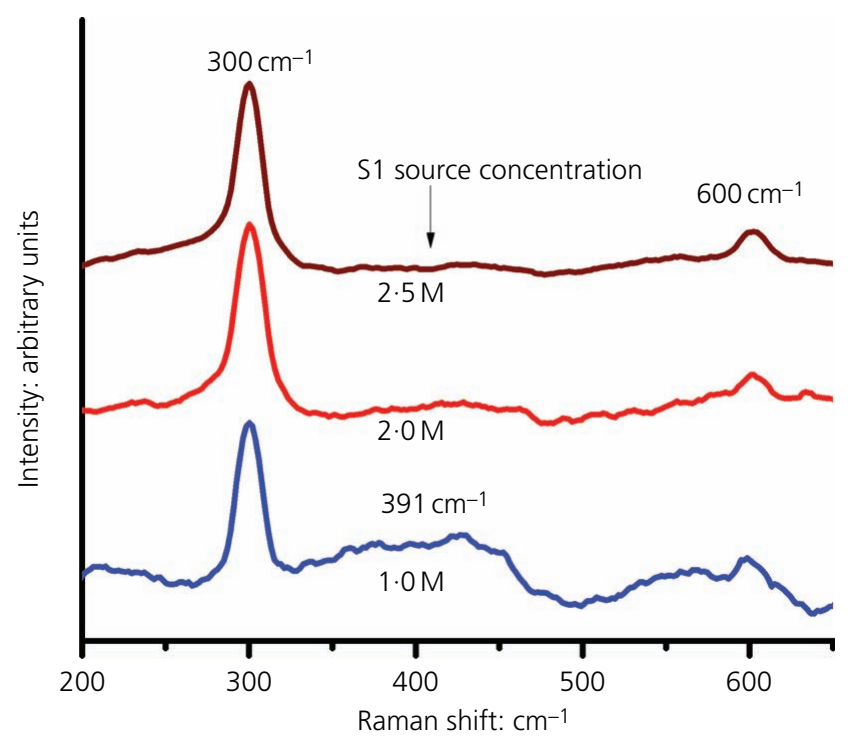

Figure 4. Raman spectra of the cadmium sulfide films synthesized at various $\mathrm{S} 1$ source concentrations

longitudinal optical (LO) phonon vibrations, which are in good agreement with those reported by Gilic et $a l^{34}$ at 305 and at $611 \mathrm{~cm}^{-1}$ for the Raman shift of the bulk cadmium sulfide crystal. In the present study, the Raman shift of cadmium sulfide film deposited at different sulfur concentration shows shifts in the LO phonon frequency from 305 to $300 \mathrm{~cm}^{-1}$ and from 611 to $600 \mathrm{~cm}^{-1}$. The redshift in the LO mode of the cadmium sulfide thin film compared with the cadmium sulfide bulk may be due to the phonon confinement effect, imperfections, impurity, valence band mixing and the non-spherical geometry of the nanostructures. ${ }^{34,35}$
The Raman shift observed at nearly $391 \mathrm{~cm}^{-1}$ corresponds to the transverse optical phonon vibration of cadmium sulfide.

\section{$3.4 \quad$ Optical properties}

The UV-Vis absorption spectra of the cadmium sulfide films recorded at room temperature are shown in Figures 5(a) and 5(b). The film deposited at different S1 source concentration shows strong absorption between 300 and $500 \mathrm{~nm}$ with the absorption edge at about $500 \mathrm{~nm}$, whereas the film deposited with S2 source concentration shows an absorption edge at nearly $490 \mathrm{~nm}$. This suggests that the bandgap energy of S2-source-synthesized cadmium sulfide films is larger than that that of films synthesized using the S1 source. The optical bandgap of the cadmium sulfide films was calculated from the dependence of the absorption coefficient $(\alpha)$ on the photon energy (hv), using Tauc's relation $(\alpha h v)=B\left(h v-E_{\mathrm{g}}\right)^{n},{ }^{36}$ where $B$ is Tauc's constant, which is a characteristic parameter independent of photon energy; $h$ is Planck's constant; $v$ is photon frequency; and $E_{\mathrm{g}}$ is the bandgap of the material. The exponent $n$ depends on the type of transition, and it takes values of $1 / 2,2,3 / 2$ and 3, corresponding to allowed direct, allowed indirect, forbidden direct and forbidden indirect transitions, respectively. As cadmium sulfide has direct allowed transitions, $n=1 / 2$ is chosen. The optical band energy of cadmium sulfide films was determined by extrapolating the straight-line portion of the graph plotting $(\alpha h v)^{2}$ against energy $(h v)$. The intercept of the extrapolated line on the energy $(h v)$ axis gives the bandgap value of the material. The bandgap of the film deposited using $\mathrm{S} 1$ and $\mathrm{S} 2$ source concentrations are estimated to be 2.20 and $2.30 \mathrm{eV}$, respectively, as shown in Figures 6(a) and 6(b), respectively. The small difference in the bandgap values may be attributed to the change in the crystallite sizes reported in Section 3.1. ${ }^{37}$ The bandgap of the cadmium

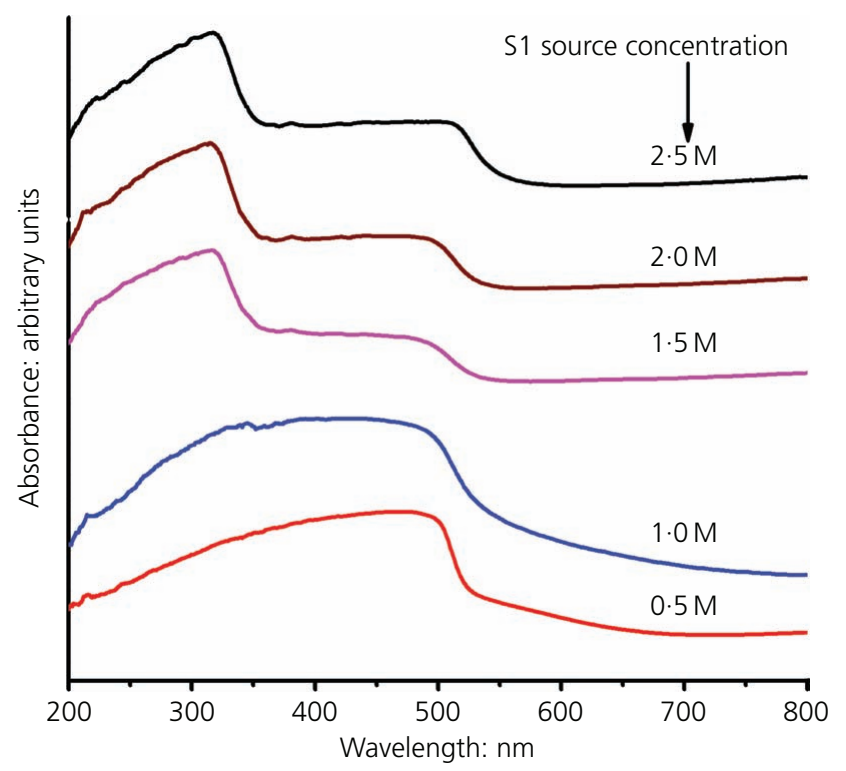

(a)

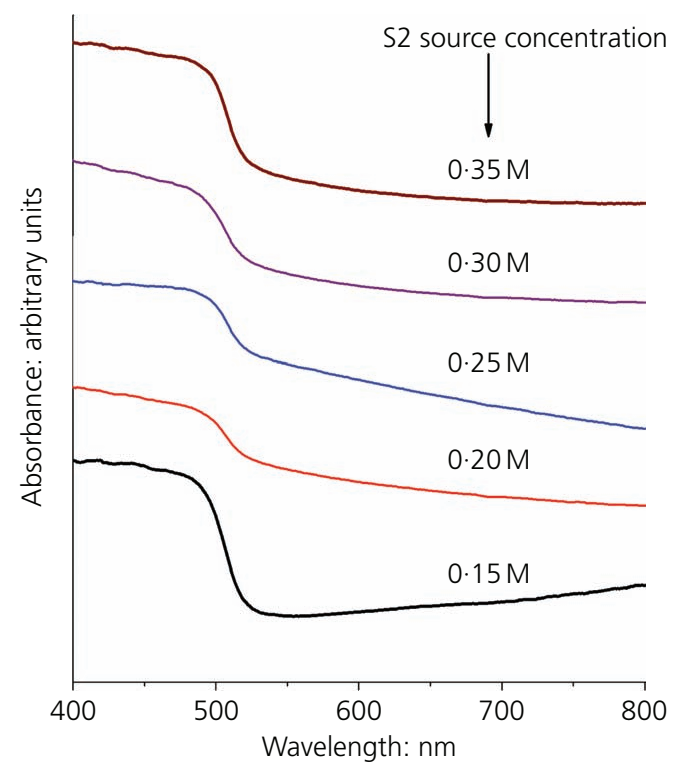

(b)

Figure 5. Absorption spectra of cadmium sulfide films synthesized at various (a) S1 and (b) S2 source concentrations 


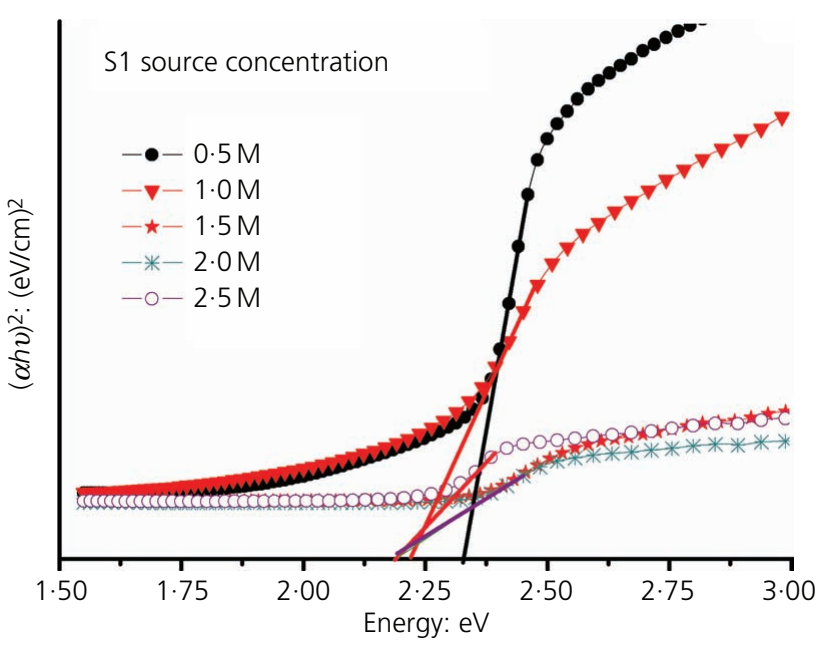

(a)

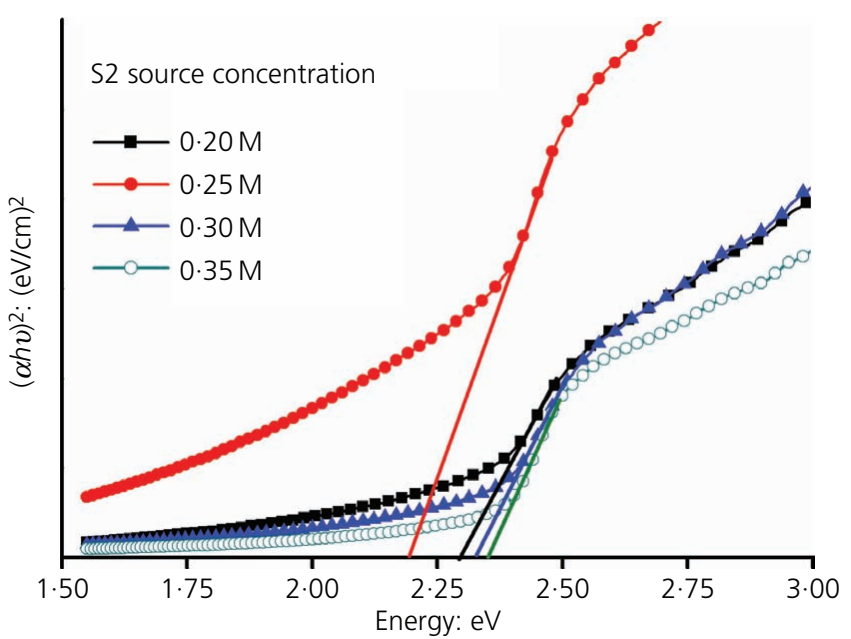

(b)

Figure 6. Tauc's plots of cadmium sulfide films synthesized at different (a) S1 and (b) S2 source concentrations

sulfide films deposited at different sulfur concentrations with S1 and S2 sulfur sources show a redshift in the bandgap in comparison with bulk cadmium sulfide $(2 \cdot 42 \mathrm{eV})$. The refractive index of the cadmium sulfide films deposited at different $\mathrm{S} 1$ and S2 sources was calculated using the Herve-Vandamme formula

1. $n=\left[1+\left(\frac{P}{E_{\mathrm{g}}+Q}\right)^{2}\right]^{1 / 2}$

where $P(=13 \cdot 6 \mathrm{eV})$ and $Q(=3 \cdot 4 \mathrm{eV})$ are constants.

The refractive index gives information about vacancies present in the deposited film and defines the measurement of density - that is, a decrease in the refractive index means a decrease in the material density in the film. ${ }^{38,39}$ The refractive indices of the films deposited at different $\mathrm{S} 1$ sources were found to be in the range 2.57-2.62. A maximum refractive index of 2.63 was calculated, corresponding to the $0.25 \mathrm{M} \mathrm{S} 2$ source concentration.

The relative density $(\rho)$ of cadmium sulfide films was calculated from the Lorentz-Lorenz relation ${ }^{5}$

2. $\rho=\left(\frac{n_{\mathrm{f}}^{2}-1}{n_{\mathrm{f}}^{2}+1}\right)\left(\frac{n_{\mathrm{b}}^{2}+1}{n_{\mathrm{b}}^{2}-1}\right)$

where $n_{\mathrm{f}}$ and $n_{\mathrm{b}}$ are the refractive indices of the synthesized cadmium sulfide film and bulk cadmium sulfide, respectively $\left(n_{\mathrm{b}}=2 \cdot 529\right)$. The calculated values of $\rho$ are 1.0101, 1.0197 and 1.0220 for the films synthesized at $0 \cdot 5,1.0$ and $1.5 \mathrm{M} \mathrm{S} 1$ source and $1 \cdot 0126,1 \cdot 0243,1 \cdot 0101$ and $1 \cdot 0077$ for the films fabricated at $020,0 \cdot 25,0 \cdot 30$ and $0 \cdot 35 \mathrm{M} \mathrm{S} 2$ source, respectively.
The extinction coefficient $(K)$ was evaluated by using a standard relation, $K=(\alpha \lambda) / 4 \Pi{ }^{40} K$ gives information about the material related to the absorbance of incident light. As seen from Figures 7(a) and 7(b), the extinction coefficient increases with photon energy and the maximum is found at nearly $2.5 \mathrm{eV}$ for the $\mathrm{S} 1$ and $\mathrm{S} 2$ sources; beyond that, $K$ decreases. It can also be seen that the extinction coefficient is maximum at $0.5 \mathrm{M} \mathrm{S} 1$ source and $0 \cdot 25 \mathrm{M} \mathrm{S} 2$ source.

\subsection{Density functional theory}

Further insights into the structure and electronic and optical properties of the cadmium sulfide nanoparticles were gained from first-principles DFT calculations. The authors considered a spherical structure of the hexagonal nanoparticles of compositions $\mathrm{Cd}_{52} \mathrm{~S}_{52}, \mathrm{Cd}_{52} \mathrm{~S}_{51}$ and $\mathrm{Cd}_{52} \mathrm{~S}_{50}$ in order to investigate the effect of sulfur concentration on the predicted electronic and optical properties. The $\mathrm{Cd}_{52} \mathrm{~S}_{51}$ and $\mathrm{Cd}_{52} \mathrm{~S}_{50}$ compositions were created by removing one and two sulfur atoms (vacancies), respectively, from the $\mathrm{Cd}_{52} \mathrm{~S}_{52}$ composition. The optimized structures of the cadmium sulfide nanoparticles with varying sulfur concentration are shown in Figures $8(\mathrm{a})-8(\mathrm{c})$. The average $\mathrm{Cd}-\mathrm{S}$ bond distance in the $\mathrm{Cd}_{52} \mathrm{~S}_{52}$ composition is predicted to be $2.532 \AA$. Small local distortion in $\mathrm{Cd}_{52} \mathrm{~S}_{51}$ and $\mathrm{Cd}_{52} \mathrm{~S}_{50}$ was observed due to the creation of sulfur vacancies, which resulted in the elongation of the $\mathrm{Cd}-\mathrm{S}$ bond distances $(2 \cdot 696 \AA)$ in the vicinity of the sulfur vacancies compared with those far away from the sulfur vacancy sites $(2 \cdot 532 \AA)$. Shown in Figures $8(\mathrm{~d})-8(\mathrm{f})$ are the corresponding electronic structures of the $\mathrm{Cd}_{52} \mathrm{~S}_{52}, \mathrm{Cd}_{52} \mathrm{~S}_{51}$ and $\mathrm{Cd}_{52} \mathrm{~S}_{50}$ nanoparticles. An analysis of the projected DOS in the valence and conduction band edges of the cadmium sulfide nanoparticles shows they are composed mainly of the sulfur $\mathrm{p}$ states. Compared to the 1:1 ratio $\mathrm{Cd}_{52} \mathrm{~S}_{52}$ composition, gap states were observed in the $\mathrm{Cd}_{52} \mathrm{~S}_{51}$ and $\mathrm{Cd}_{52} \mathrm{~S}_{50}$, which can be attributed to the presence of sulfur vacancy effects. The bandgaps of the $\mathrm{Cd}_{52} \mathrm{~S}_{52}, \mathrm{Cd}_{52} \mathrm{~S}_{51}$ and $\mathrm{Cd}_{52} \mathrm{~S}_{50}$ nanoparticles are predicted to be $2 \cdot 38,2 \cdot 52$ and 

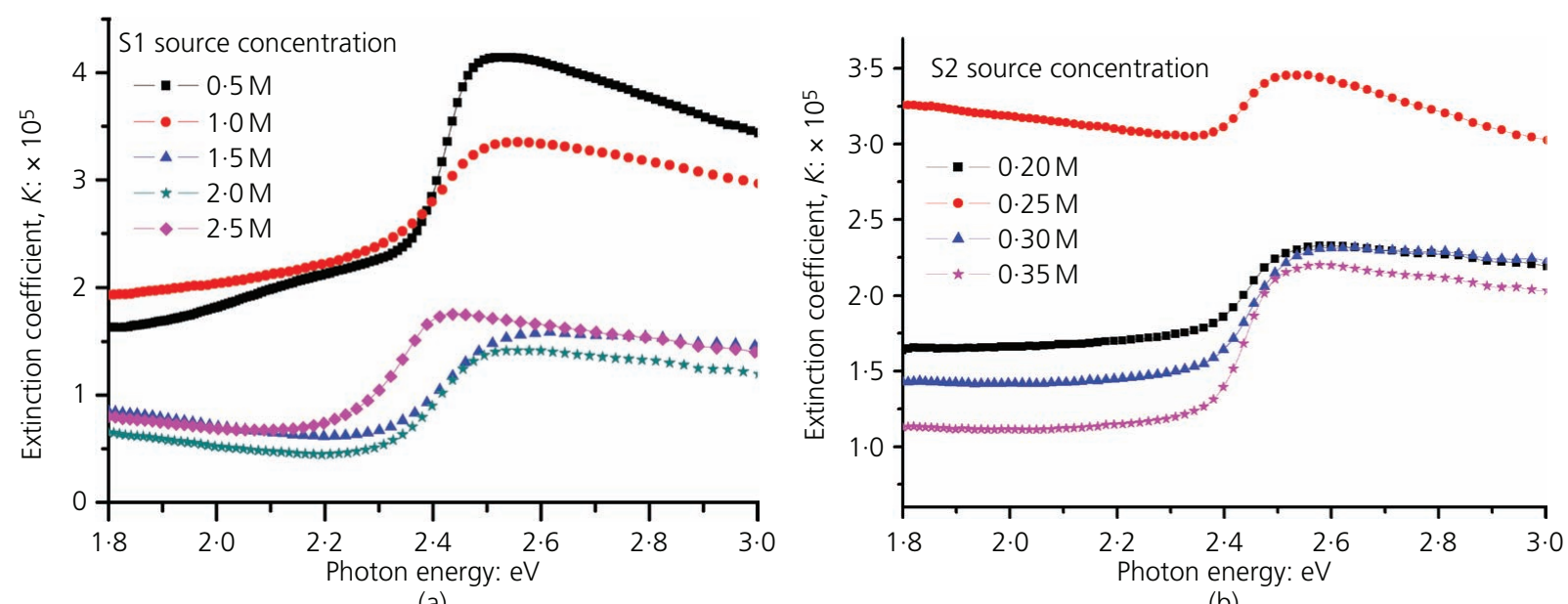

(a)

(b)

Figure 7. Plot of the extinction coefficient as a function of photon energy for cadmium sulfide films at different (a) S1 and (b) S2 source concentrations

$2 \cdot 65 \mathrm{eV}$, respectively, indicating that the bandgap increases with decreasing sulfur concentration.

To gain further insight into the optical properties of the cadmium sulfide nanoparticles with decreasing sulfur content, the frequencydependent dielectric function $\varepsilon(\omega)=\varepsilon_{1}(\omega)+i \varepsilon_{2}(\omega)$ at energy was computed. The optical properties of semiconducting materials are inherently linked to their electronic properties; hence, the predicted differences in the electronic bandgaps are expected to dictate the optical properties of the cadmium sulfide nanoparticles. The calculated real (dispersive, $\varepsilon_{1}$ ) and imaginary (absorptive, $\varepsilon_{2}$ ) parts of the dielectric function for cadmium sulfide nanoparticles are shown in Figures 9(a)-9(c). From the real part of the dielectric function, the dielectric constants of the $\mathrm{Cd}_{52} \mathrm{~S}_{52}, \mathrm{Cd}_{52} \mathrm{~S}_{51}$ and $\mathrm{Cd}_{52} \mathrm{~S}_{50}$ nanoparticles are calculated to be $9 \cdot 48,7 \cdot 19$ and $6 \cdot 17$, respectively. The absorbance of $\mathrm{Cd}_{52} \mathrm{~S}_{52}, \mathrm{Cd}_{52} \mathrm{~S}_{51}$ and $\mathrm{Cd}_{52} \mathrm{~S}_{50}$

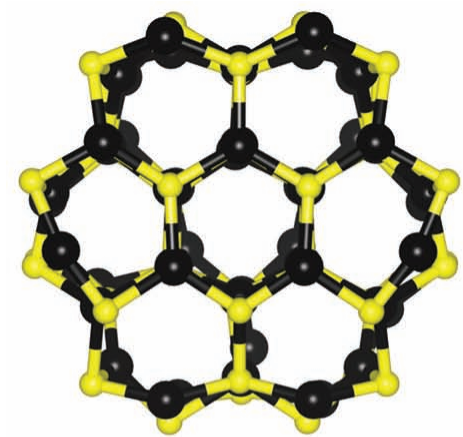

(a)

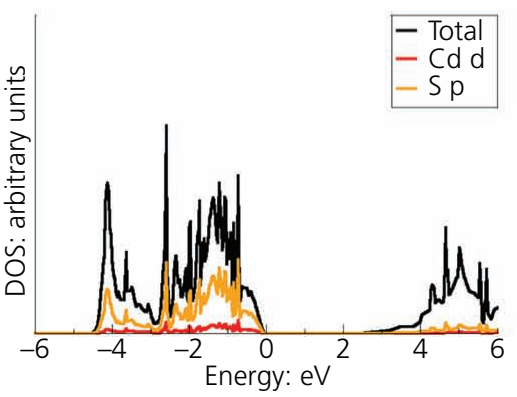

(d)

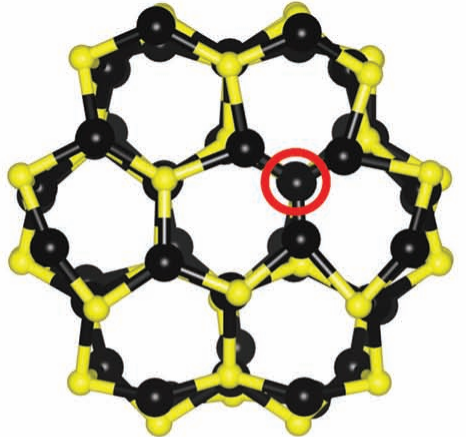

(b)

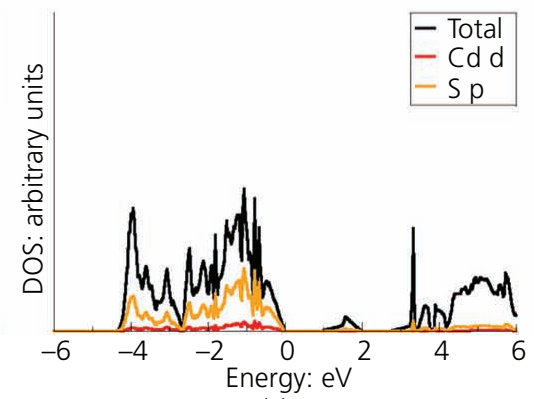

(e)

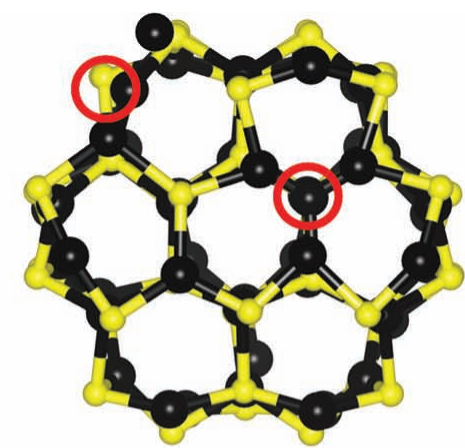

(c)

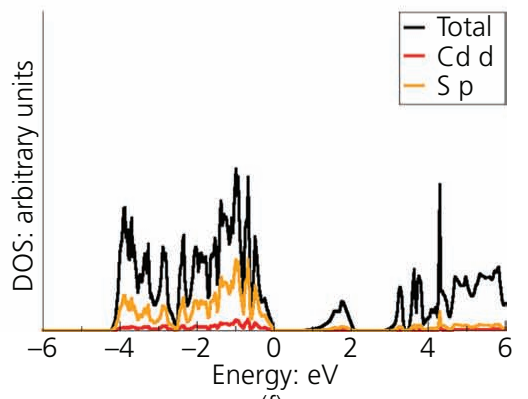

(f)

Figure 8. Optimized structures of the cadmium sulfide nanoparticles with varying sulfur concentrations: (a) $\mathrm{Cd}_{52} \mathrm{~S}_{52}$; (b) $\mathrm{Cd}_{52} \mathrm{~S}_{51}$; (c) $\mathrm{Cd}_{52} \mathrm{~S}_{50}$. The sulfur vacancy sites are denoted by the red circles. The corresponding DOS projected on the cadmium $d$ and sulfur $p$ states are shown in $(d)-(f)$. Color scheme: cadmium, black; sulfur, yellow 


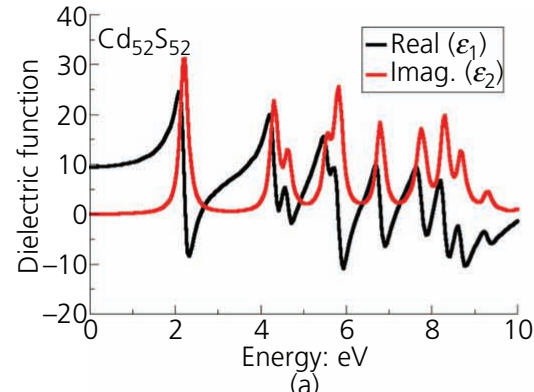

(a)

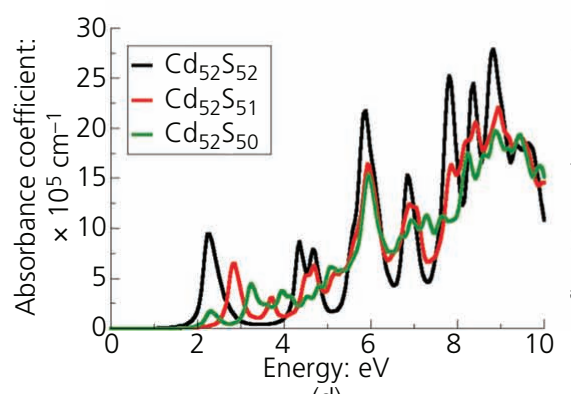

(d)

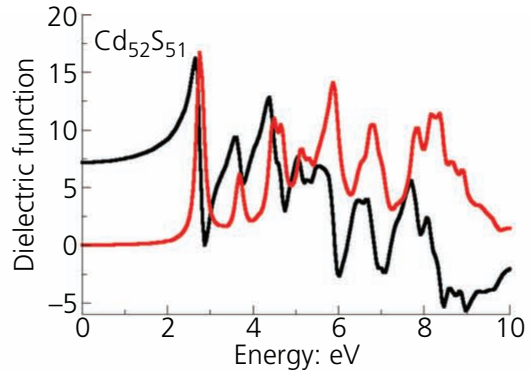

(b)

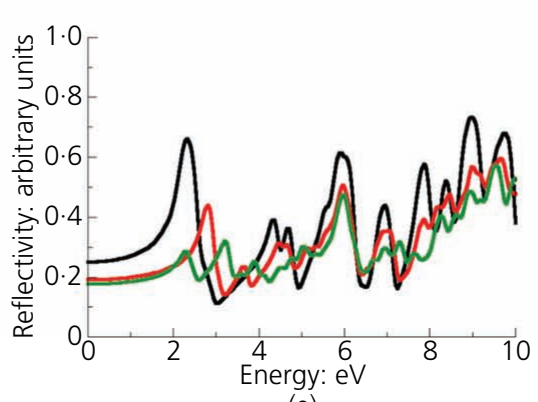

(e)

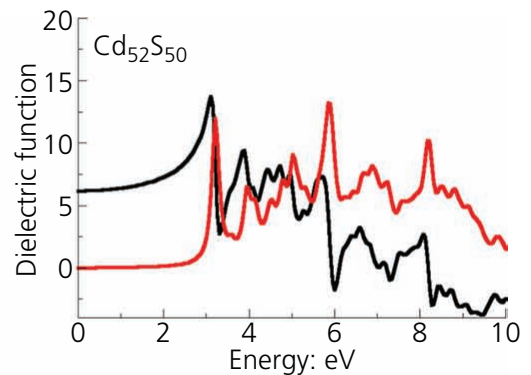

(c)

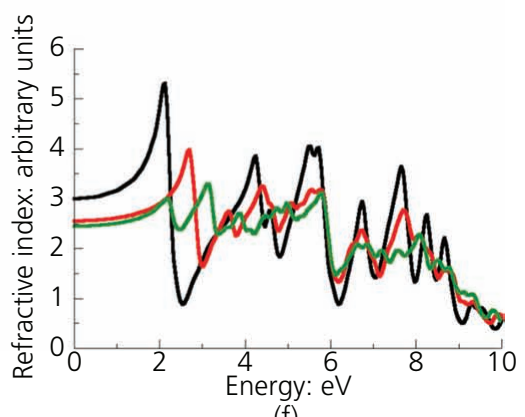

(f)

Figure 9. Calculated dielectric functions of (a) $\mathrm{Cd}_{52} \mathrm{~S}_{52}$, (b) $\mathrm{Cd}_{52} \mathrm{~S}_{51}$ and (c) $\mathrm{Cd}_{52} \mathrm{~S}_{50}$ nanoparticles and the corresponding (d) absorbance, (e) reflectivity and (f) refractive index

nanoparticles (Figure 9(d)) starts just after $2 \mathrm{eV}$, which is close to their fundamental bandgaps, but in general, a higher absorbance is predicted for the $\mathrm{Cd}_{52} \mathrm{~S}_{52}$ nanoparticle in the visible light region, which is consistent with its smaller bandgap than that of the $\mathrm{Cd}_{52} \mathrm{~S}_{51}$ and $\mathrm{Cd}_{52} \mathrm{~S}_{50}$ nanoparticles. A higher reflectivity is also observed for the $\mathrm{Cd}_{52} \mathrm{~S}_{52}$ nanoparticle (25\%) than those for the $\mathrm{Cd}_{52} \mathrm{~S}_{51}(19 \%)$ and $\mathrm{Cd}_{52} \mathrm{~S}_{50}$ (18\%) nanoparticles (Figure 9(e)). A higher refractive index is also predicted for the $\mathrm{Cd}_{52} \mathrm{~S}_{52}$ nanoparticle (3.01) than for the $\mathrm{Cd}_{52} \mathrm{~S}_{51}(2 \cdot 56)$ and $\mathrm{Cd}_{52} \mathrm{~S}_{50}(2 \cdot 45)$ nanoparticles (Figure 9(f)).

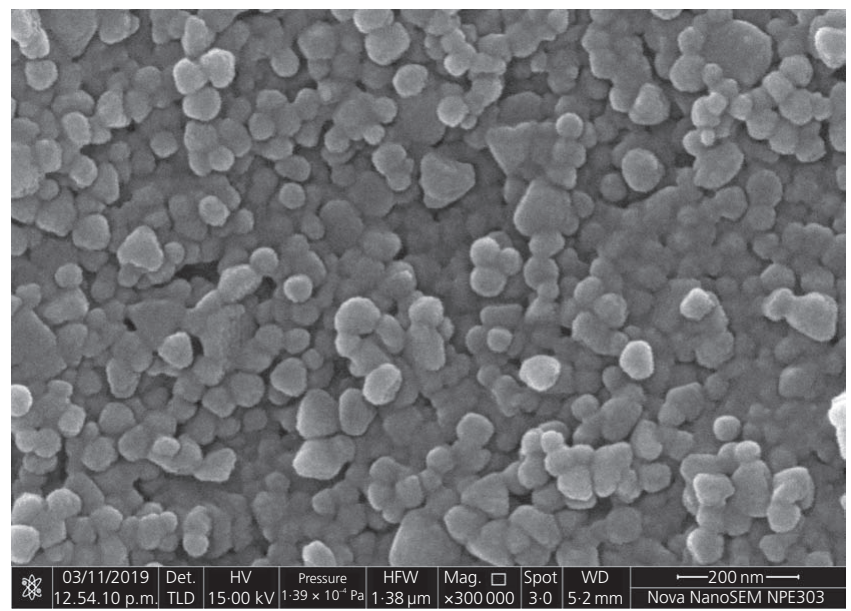

(a)

\subsection{Field-emission scanning electron microscopy analysis}

Figure 10(a) is the field-emission scanning electron microscopy (FESEM) image of a cadmium sulfide film synthesized using $2.5 \mathrm{M} \mathrm{S} 1$ source concentration, and Figure $10(\mathrm{~b})$ is the FESEM image of a cadmium sulfide film synthesized using $0.35 \mathrm{M}$ S2 source concentration. The cadmium sulfide film deposited at $2.5 \mathrm{M}$ sulfur source (S1) reveals highly agglomerated, densely packed, smooth, uniform and spherical nanoparticles (Figure 10(a)). Vertically oriented rod-like structures

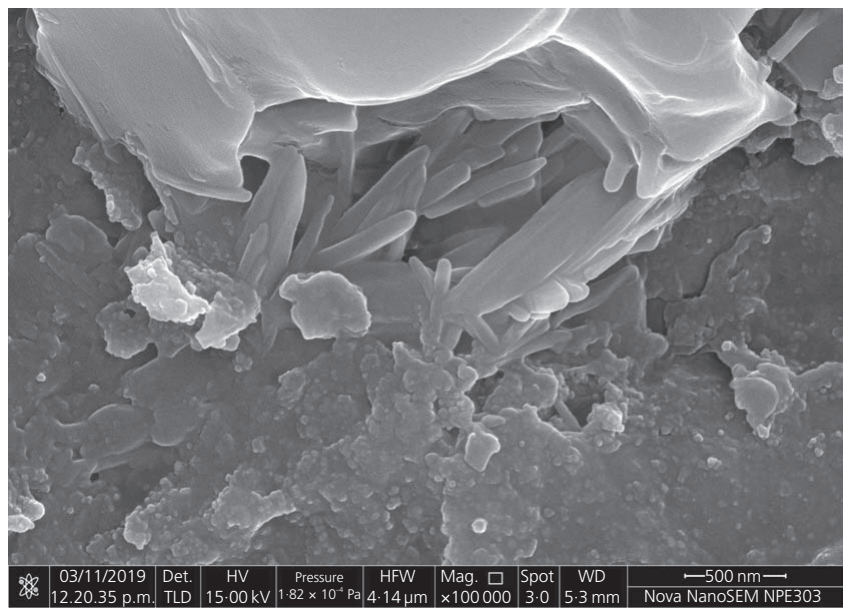

(b)

Figure 10. Field-emission scanning electron microscopy images of cadmium sulfide films synthesized using (a) $2.5 \mathrm{M} \mathrm{S1}$ and (b) $0.35 \mathrm{M} \mathrm{S2}$ source concentrations 
(Figure 10(b)) were obtained. The larger grains are formed by a combination of smaller grains, which may lead to increment in the diffusion length of the charge carriers by providing a conducting link when the cadmium sulfide film is deposited using S2 sulfur source. ${ }^{41}$ It can thus be concluded from the FESEM analysis that the morphology of cadmium sulfide films can be tuned by the sulfur source.

\section{Conclusion}

High-quality cadmium sulfide nanoparticles were successfully synthesized using HIM and films deposited on a soda lime glass substrate using the doctor blade method. The influence of sulfur concentration with S1 and S2 sulfur sources on the structural, morphological and optoelectronic properties of the cadmium sulfide films was investigated in detail. Formation of hexagonal cadmium sulfide was confirmed by XRD, FTIR and Raman analyses. The maximum crystallite size of cadmium sulfide was found to be $37.5 \mathrm{~nm}$ in the case of the S2 source with $0.25 \mathrm{M}$ sulfur concentration. The UV-Vis spectroscopic analysis showed that the cadmium sulfide films exhibited a redshift in absorption edge compared with bulk cadmium sulfide. A maximum refractive index of 2.63 was observed, corresponding to the $0.25 \mathrm{M}$ concentration for the $\mathrm{S} 2$ source. The FESEM studies showed that the morphology of cadmium sulfide is sulfur source dependent. First-principles DFT calculations predict the bandgaps of cadmium sulfide nanoparticles to increase with decreasing sulfur concentration $-\mathrm{Cd}_{52} \mathrm{~S}_{52}$ $(2 \cdot 38 \mathrm{eV}) \mathrm{Cd}_{52} \mathrm{~S}_{51}(2.52 \mathrm{eV})$ and $\mathrm{Cd}_{52} \mathrm{~S}_{50}(2.65 \mathrm{eV})-$ and the differences in the electronic properties were shown to influence the optical properties of the cadmium sulfide nanoparticles. The morphology-controlled synthesis of cadmium sulfide thin films using S1 and S2 sulfur sources provides a promising approach to the synthesis of cadmium sulfide nanoparticles with tailored morphology and optoelectronic properties. Thus, from the present study, it is concluded that the synthesized cadmium sulfide thin film was more suitable for n-type window layers for cadmium sulfide solar cells and electron-transport layers in PSCs.

\section{Acknowledgements}

N. Y. D. acknowledges the UK Engineering and Physical Sciences Research Council for funding (grant. EP/S001395/1). This work has also used the computational facilities of the Advanced Research Computing at Cardiff, Cardiff University, and High Performance Computing Wales. The authors gratefully acknowledge the financial support by the Ministry of New and Renewable Energy, Government of India, for a fellowship under the National Renewable Energy Fellowship program. The author A. M. F. acknowledges Exide Industries Limited for establishment and use of facilities at Exide - Savitribai Phule Pune University Centre of Excellence in Energy Storage at the Savitribai Phule Pune University Campus.

\section{REFERENCES}

1. Guerrero-Lemus R and Shephard LE (2017) Photovoltaics. In Lowcarbon Energy in Africa and Latin America: Renewable
Technologies, Natural Gas and Nuclear Energy. Springer, Cham, Switzerland, pp. 149-173.

2. NREL (National Renewable Energy Laboratory) (2020) Best Researchcell Efficiencies. NREL, Golden, CO, USA. See https://www.nrel.gov/ pv/assets/pdfs/best-research-cell-efficiencies.190416.pdf (accessed 10/01/2020).

3. Purohit A, Chander S and Dhaka MS (2018) Thermal evolution of physical properties of evaporated CdS thin films for perovskite solar cell applications. Vacuum 153: 35-38.

4. Chander S and Dhaka MS (2017) Optimization of substrates and physical properties of CdS thin films for perovskite solar cell applications. Journal of Materials Science: Materials in Electronics 28(9): 6852-6859.

5. Chander S and Dhaka MS (2017) Optical and structural constants of $\mathrm{CdS}$ thin films grown by electron beam vacuum evaporation for solar cells. Thin Solid Films 638: 179-188.

6. Qutub N and Sabir S (2012) Optical, thermal and structural properties of CdS quantum dots synthesized by a simple chemical route. International Journal of Nanoscience and Nanotechnology 8(2): 111-120.

7. Zhang $H$ (2016) Effects of post-annealing treatment on the structure and photoluminescence properties of CdS/PS nanocomposites prepared by sol-gel method. Optoelectronic Letters 12(2): 81-84.

8. Chen R, Han B, Yang L et al. (2016) Controllable synthesis and characterization of CdS quantum dots by a microemulsion-mediated hydrothermal method. Journal of Luminescence 172: 197-200.

9. Ren B, Cao M, Zhang Q et al. (2016) Controllable synthesis of CdS nanowire by a facile solvo thermal method and its temperature dependent photoluminescent property. Journal of Alloys and Compounds 659: 74-81.

10. Elavarthi $P$, Kumar AA, Murali G, Reddy DA and Gunasekhar KR (2016) Room temperature ferromagnetism and white light emissive $\mathrm{CdS}: \mathrm{Cr}$ nanoparticles synthesized by chemical co-precipitation method. Journal of Alloys and Compounds 656: 510-517.

11. Darwish M, Mohammadi A and Assi N (2016) Microwave-assisted polyol synthesis and characterization of PVP-capped CdS nanoparticles for the photocatalytic degradation of tartrazine. Materials Research Bulletin 74: 387-396.

12. Denisca UV, Gamulin O, Tonej A et al. (2001) CdS nanocrystals formed in $\mathrm{SiO}_{2}$ substrates by ion implantation. Materials Science and Engineering: C 15(1-2): 105-107.

13. Yang H, Huang C, Li X, Shi R and Zhang K (2005) Luminescent and photocatalytic properties of cadmium sulfide nanoparticles synthesized via microwave irradiation. Materials Chemistry and Physics 90(1): 155-158.

14. Miskin CK, Yang WC, Hages CJ, Shi R and Zhang K (2015) $9.0 \%$ efficient $\mathrm{Cu}_{2} \mathrm{ZnSn}(\mathrm{S}, \mathrm{Se})_{4}$ solar cells from selenized nanoparticle inks. Progress in Photovoltaics: Research and Applications 23(5): 654-659.

15. Kresse G and Joubert D (1999) From ultrasoft pseudopotentials to the projector augmented-wave method. Physical Review B 59(3): $1758-1775$

16. Kresse G and Furthmüller J (1996) Efficiency of ab-initio total energy calculations for metals and semiconductors using a plane-wave basis set. Computational Materials Science 6(1): 15-50.

17. Perdew JP, Burke K and Ernzerhof M (1997) Generalized gradient approximation made simple. Physical Review Letters 78(7): 1396-1399.

18. Blöchl PE (1994) Projector augmented-wave method. Physical Review $B$ 50(24): 17953-17997.

19. Koelling DD and Harmon BN (1977) A technique for relativistic spinpolarized calculations. Journal of Physics C: Solid State Physics 10(16): article 3107.

20. Krukau AV, Vydrov OA, Izmaylov AF and Scuseria GE (2006) Influence of the exchange screening parameter on the performance of screened hybrid functionals. Journal of Chemical Physics 125(22): article 224106 . 
Nanomaterials and Energy

Volume 9 Issue 1
Optical, structural and morphological study of CdS nanoparticles: role of sulfur source

Kamble, Rondiya, Bade et al.
21. Blöchl PE, Jepsen $O$ and Andersen OK (1994) Improved tetrahedron method for Brillouin-zone integrations. Physical Review B 49(23): $16223-16233$.

22. Peng ZA and Peng X (2002) Nearly monodisperse and shapecontrolled CdSe nanocrystals via alternative routes: nucleation and growth. Journal of the American Chemical Society 124(13): 3343-3353.

23. Nieto-Zepeda KE, Guillén-Cervantes, Rodríguez-Rosales K et al. (2017) Effect of the sulfur and fluorine concentration on physical properties of CdS films grown by chemical bath deposition. Results in Physics 7: 1971-1975.

24. Ghorpade U, Suryawanshi M, Shin SW et al. (2014) Towards environmentally benign approaches for the synthesis of CZTSSe nanocrystals by a hot injection method: a status review. Chemical Communications 50(77): 11258-11273.

25. Yeh CY, Lu ZW, Froyen S and Zunger A (1992) Zinc-blende-wurtzite polytypism in semiconductors. Physical Review B 46(16): 10086-10097.

26. Verma AK, Chandra P, Srivastava A and Shukla RK (2017) Optoelectronic studies of commercially and lab prepared cadmium sulfide chalcogenide. Research \& Reviews: Journal of Material Sciences 5(2): 28-34.

27. Delacruz Terrazas EC, Ambrosio RC, Mota González ML et al. (2015) A simple method for the synthesis of CdS nanoparticles using a novel surfactant. Chalcogenide Letters 12(4): 147-153.

28. Mir FA, Chattarjeeb I, Darc AA, Asokan K and Bhat GM (2015) Preparation and characterizations of cadmium sulfide nanoparticles. Optik 126: 1240-1244.

29. Krylova V and Dukstiene N (2019) The structure of PA-Se-S-Cd composite materials probed with FTIR spectroscopy. Applied Surface Science 470: 462-471.

30. Sabah A, Siddiqi SA and Salamat A (2010) Fabrication and characterization of CdS nanoparticles annealed by using different radiations. International Scholarly and Scientific Research \& Innovation 4(9): 532-553.
31. Li Y and Yang G (2004) Studies on molecular composites of polyamide 6/polyamide 66. Macromolecular Rapid Communications 25(19): 1714-1718.

32. Rao GT, Babu B, Stella RJ et al. (2015) Synthesis and characterization of $\mathrm{VO}^{2+}$ doped $\mathrm{ZnO}-\mathrm{CdS}$ composite nanopowder. Journal of Molecular Structure 1081: 254-259.

33. Shi Y, Liu L, Tu C et al. (2011) Facile preparation of CdS quantum dots using hyperbranched poly(amidoamine)s with hydrophobic endgroups as nanoreactors. Journal of Applied Polymer Science 122(2): 1077-1083.

34. Gilic M, Trajic J, Romevic N et al. (2013) Optical properties of CdS thin films. Optical Materials 35(5): 1112-1117.

35. Owens FJ and Poole CP (2007) Introduction to Nanotechnology. Wiley, Hoboken, NJ, USA.

36. Tauc J (1972) Optical properties of solids. In Optical Properties of Solids (Abeles F (ed.)). North Holland, Amsterdam, the Netherlands, pp. 277-310.

37. Rodríguez-Rosales K, Quiñones-Galván JG, Guillén-Cervantes A et al. (2017) Nanocrystalline-CdS thin films grown on flexible PETsubstrates by chemical bath deposition. Materials Research Express 4(7): article 075904.

38. Chander S, Purohit A, Lal C and Dhaka MS (2017) Enhancement of optical and structural properties of vacuum evaporated CdTe thin films. Materials Chemistry and Physics 185: 202-209.

39. Chander S and Dhaka MS (2017) Thermal annealing induced physical properties of electron beam vacuum evaporated CdZnTe. Thin Solid Films 625: 131-137.

40. Kariper A, Güneri E, Göde F, Gümüş C and Özpozan T (2011) The structural, electrical and optical properties of CdS thin films as a function of $\mathrm{pH}$. Materials Chemistry and Physics 129(1-2): 183-188.

41. Chander S and Dhaka MS (2018) $\mathrm{CdCl}_{2}$ treatment concentration evolution of physical properties correlation with surface morphology of CdTe thin films for solar cells. Materials Research Bulletin 97: $128-135$.

\section{How can you contribute?}

To discuss this paper, please submit up to 500 words to the journal office at journals@ice.org.uk. Your contribution will be forwarded to the author(s) for a reply and, if considered appropriate by the editor-in-chief, it will be published as a discussion in a future issue of the journal.

ICE Science journals rely entirely on contributions from the field of materials science and engineering. Information about how to submit your paper online is available at www.icevirtuallibrary.com/page/authors, where you will also find detailed author guidelines. 